\title{
CAN LOW DOSE OF ISOTRETINOIN CAUSE DEPRESSION
}

\author{
Kasim S. Al-Chalabi ${ }^{1} \quad$ Haitham B. Fathi $^{2} \quad$ Mohammed N. Al-Mallah ${ }^{3}$
}

\section{Abstract}

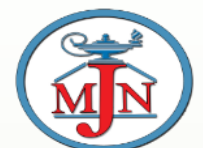

Background: Depressive symptom may associate with daily recommended dose of Isotretinoin for nodulocystic acne. Does reducing the dose will reduce the incidence of depressive symptoms is still not clearly understood.

Study objective: To compare the types and frequency of depressive symptoms among patients with nodulocystic acne receiving three different low doses of isotretinoin (10mg daily, 20mg every other day, and 20mg daily).

Study design: Open randomized clinical trial.

Study setting: Dermatology clinic at Ibn Sina teaching hospital

Patients \& methods: 169 patients with severe nodulocystic acne were randomly assigned to one of three isotretinoin regimen groups as follows: $10 \mathrm{mg}$ daily $(n=46), 20 \mathrm{mg}$ alternate day $(n=58)$, and 20 mg daily $(n=65)$. After a month of treatment, patient assessed for degree of improvement of acne and incidence of depressive symptoms

Results: The frequencies of depressive symptoms irrespective to group were as follows: crying in 36 $(21.3 \%)$, anger in $35(20.7 \%)$, sleep disturbance in $32(18.9 \%)$, isolation in $29(17.1 \%)$, and sadness in $20(11.8 \%)$ of patients. The frequency of crying, anger and sadness were significantly rose with increase dose of isotretinoin from $10 \mathrm{mg}$ to $20 \mathrm{mg}$ daily (p-value equal to $0.02,0.02$, and 0.001 respectively).The summated depressive symptoms rose from ( 0.52 symptoms) in $10 \mathrm{mg}$ daily to (1.19 symptoms) in $20 \mathrm{mg}$ daily dose and the difference was statistically significant.

Conclusion: Depressive symptoms increased gradually with increase dose of isotretinoin and reducing the dose to least effective dose is mandatory.

Key Words: isotretinoin, dose regimen, depression, nodulocystic acne.

\footnotetext{
${ }^{1}$ M.B.Ch.B F.A.B.H.S., Department of Medicine, Mosul College of Medicine, University of Mosul, Mosul, Iraq.

${ }^{2}$ M.B.Ch.B, MSc, Department of Medicine, Ninevah College of Medicine, University of Ninevah, Mosul, Iraq.

${ }^{3}$ M.B.Ch.B F.A.B.H.S. Department of Medicine, Ninevah College of Medicine, University of Ninevah, Mosul, Iraq.
} 


\section{INTRODUCTION}

Isotretinoin is an efficacious and widely-used systemic therapy for severe recalcitrant nodulocystic acne lesions". But the proverb "no rose without thorn" is applicable to it. Early after its release on the market, isotretinoin use was linked to wide ranges of adverse effects at the recommended daily dose $(0.5-1 \mathrm{mg} /$ $\mathrm{kg})^{2}$.

One of these adverse effects was the psychiatric symptoms ${ }^{3}$. Since the $90 \mathrm{~s}$ of last century many case reports, short case series studies, reports from the Adverse Drug Event Reporting Systems (ADERS) linked depression and suicidality to the use of isotretinoin have been accumulated in US Food and Drug Administration $(\text { FDA })^{4}$. But, later larger studies and meta-analysis reports revealed considerable controversy regarding a proposed causal relationship between isotretinoin and depression ${ }^{\mathbf{5}}$. Now a day there is marked debate among researchers regarding presence ${ }^{6}$ or absence of this association ${ }^{7}$. Even those who support the presence of this relation vary in explaining its relation to the dose. Some suggest dosedependent relation, while other considered as idiosyncratic relation.
These controversies prompt us to conduct this study aiming to elaborate incidence and types of depressive symptoms in acne patients using three different small doses of isotretinoin.

\section{Study objective:}

To compare the types and frequency of depressive symptoms among nodulocystic acne patients receiving three different low doses of isotretinoin (10mg daily, 20mg every other day, and $20 \mathrm{mg}$ daily).

\section{Patients and methods}

The study was conducted as open randomized clinical trial. All patients with recalcitrant, extensive and nodulocystic acne who attended to dermatology clinic at Ibn Sina teaching hospital during Jan. 1 - April 30, 2018 were asked to participate in the study. One hundred sixty nine patients were eligible and accept to participate in the current study. Baseline screening tests of liver, kidney and lipid profile was done to the all patients. Furthermore, pregnancy test was done to married female patients. The recruited patients were randomly assigned into one of three treatment regimen groups. The first group used Isotretinoin 10mg daily, the second group used Isotretinoin $20 \mathrm{mg}$ every other day, and 
the last group used Isotretinoin $20 \mathrm{mg}$ daily. After a month of treatment, patient assessed for outcome measures. The data collected include (severity of acne, degree of xerosis, chelititis, and presence or absence of depressive symptoms. Data were processed by the use of statistical package SPSS Ver 18 (SPSS Inc., Chicago, Ill). Different descriptive statistical methods were used to summarize and tabulate the data. A chi square test was used assess difference in frequency of depressive symptoms among three treatment groups. The difference in sum of depressive symptoms among three groups were compared using Kruskall Wallis test. A p-value <0.05 was considered statistically significant.

\section{RESULTS}

One hundred sixty nine patients with severe nodulocystic acne participate in the study. Their age range from 14- 27 years with mean (SD) of 19.5 (2.0) years. They are consisted of 42 $(24.9 \%)$ males and $127 \quad(75.1 \%)$ females. Each patient was allocated into one of the three schedules of the study. Table 1 shows the distribution of demographic characteristics of the participants in each group. Results reveal small but not significant differences among three groups regarding age, weight and gender (pvalue $0.08,0.09 .0 .07$ respectively). 
Table 1. Comparison of demographic characteristics of patients with nodulocystic acne among the three isotretinoin doses and schedules groups

\begin{tabular}{|c|c|c|c|c|}
\hline \multirow[b]{2}{*}{ Characteristic } & \multicolumn{3}{|c|}{ Isotretinoin doses \& schedules } & \multirow[b]{2}{*}{ P-value } \\
\hline & $\begin{array}{c}10 \mathrm{mg} \\
\text { daily } \\
\mathrm{N}=46\end{array}$ & $\begin{array}{c}20 \mathrm{mg} \\
\text { alternate day } \\
\mathrm{N}=58\end{array}$ & $\begin{array}{l}20 \mathrm{mg} \\
\text { daily } \\
\mathrm{N}=65\end{array}$ & \\
\hline Age, mean (SD) & $21.73(1.79)$ & $19.06(2.04)$ & $20.35(1.94)$ & 0.08 \\
\hline Weight, mean (SD) & $59.68(11.52)$ & $61.13(16.39)$ & $58.75(11.54)$ & 0.09 \\
\hline \multicolumn{5}{|l|}{ Gender, No. (\%) } \\
\hline Male & $11(13.05 \%)$ & $20(34.5 \%)$ & $16(24.6 \%)$ & 0.07 \\
\hline Female & $40(87.0 \%)$ & $38(65.5 \%)$ & $49(75.4 \%)$ & \\
\hline
\end{tabular}

Table 2. Comparison of frequencies of depressive symptoms among different isotretinoin doses and schedules regimen for severe nodulocystic acne

\begin{tabular}{lcccccc}
\hline & \multicolumn{3}{c}{ Isotretinoin doses \& schedules } & & Total \\
\cline { 2 - 4 } \multicolumn{1}{c}{ Depressive symptoms } & $\begin{array}{c}\mathbf{1 0} \mathbf{~ m g} \\
\text { daily } \\
\mathbf{N = 4 6}\end{array}$ & $\begin{array}{c}\mathbf{2 0} \mathbf{~ m g} \\
\text { alternate day } \\
\mathbf{N = 5 8}\end{array}$ & $\begin{array}{c}\mathbf{2 0 m g} \\
\text { daily } \\
\mathbf{N = 6 5}\end{array}$ & & $\begin{array}{c}\text { P- } \\
\text { N=169 }\end{array}$ & value \\
& $4(8.7 \%)$ & $14(24.1 \%)$ & $18(27.7 \%)$ & $36(21.3 \%)$ & 0.02 \\
Crying & $4(8.7 \%)$ & $12(20.7 \%)$ & $13(20.0 \%)$ & $29(17.1 \%)$ & 0.1 \\
Isolation & $6(13.0 \%)$ & $12(20.7 \%)$ & $14(21.5 \%)$ & $32(18.9 \%)$ & 0.5 \\
Sleep disturbance & $8(17.4 \%)$ & $8(13.8 \%)$ & $19(29.2 \%)$ & $35(20.7 \%)$ & 0.02 \\
Anger & $2(4.3 \%)$ & $4(6.9 \%)$ & $14(21.5)$ & $20(11.8 \%)$ & 0.001 \\
Sadness & & &
\end{tabular}

The frequencies of depressive symptoms reported by the patients are shown in Table 2. The result reveal that most frequent depressive symptom reported by the patient irrespective to dose they received was the unexplained bout of crying reported by $36(21.3 \%)$ of patients, while the least frequent symptom was feeling of sadness reported by $20(11.8 \%)$ of patients. In general the frequencies of depressive symptoms in descending manner were as follows: crying episode, recurrent bout of anger, sleep disturbance, feel isolated and lastly, feel sadness. Taking the dose of isotretinoin in consideration reveal that doubling the dose from $10 \mathrm{mg}$ daily to $20 \mathrm{mg}$ daily yield: tripling the frequency of crying episode, doubling frequency of feeling isolated, one and half times raise in suffering from sleep disturbance and anger bout, and lastly, five times more frequency of feeling sad. The frequency of crying, anger and sadness were significantly rose with increase dose of isotretinoin (pvalue equal to $0.02,0.02$, and 0.001 respectively). 
Figure 1 depicts the average and 95\%

CI of summated depressive symptom in each study group. The result show gradual raises in mean of summated depressive symptom with increase dose of isotrtinoin. The average summated symptom was $(0.522$ symptoms) in $10 \mathrm{mg}$ daily dose which rose to 0.862 (symptoms) in $20 \mathrm{mg}$ alternate day schedule to reach its peak (1.196 symptoms) in $20 \mathrm{mg}$ daily dose.
Analysis of variance shows a significant difference in average summated depressive among three group of the study $(\mathrm{p}$-value $=0.05)$. A post hoc analysis to determine the nonhomogenous group shows significant difference between $10 \mathrm{mg}$ daily dose and $20 \mathrm{mg}$ daily dose. The rest of differences between groups were statistically not significant.

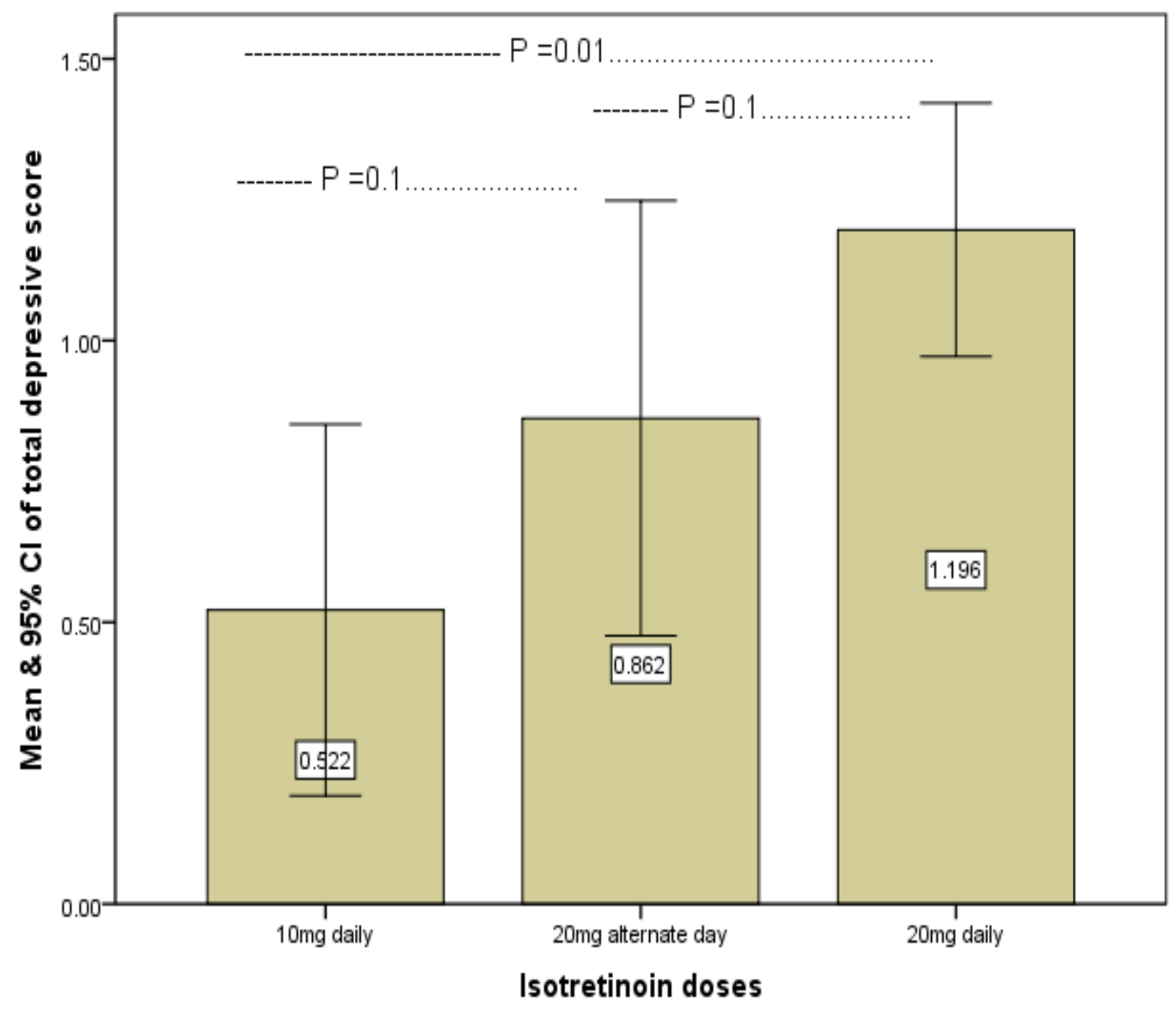

Error bars: $95 \% \mathrm{Cl}$

Fig 1. Comparison of mean and 95\% CI of summated depressive symptoms among different isotretinoin doses and schedules regimen for severe nodulocyctic acne 


\section{DISCUSSION}

Isotretinoin is very effective treatment of acne and disorders of keratinization in the routine clinical $\operatorname{dose}^{8}$. The result of this open trail revealed that lowering the dose of isotretinoin below $0.5 \mathrm{mg} /$ $\mathrm{kg} /$ day like 10-20mg daily can preserve the effectiveness of isotretinoin. This finding is consistent with conclusion of recent randomized trial that reports minor non-significant difference in effectiveness of isotretinoin in conventional $(0.5$ $\mathrm{mg} / \mathrm{kg} /$ day $)$, low-dose $(0.25 \mathrm{mg} / \mathrm{kg} /$ day $)$ and or intermittent $(0.5 \mathrm{mg} / \mathrm{kg}$ daily for one week every four weeks) oral dose in the treatment of acne?

In this series of 169 acne patients, $75 \%$ of them were adolescent females. Although this is not properly conducted epidemiological study, but the adolescent female preponderance in this series tells us two things: first, there is a general misconception that "acne only affects teenagers". Significant proportion of adults continues to be plagued by acne well beyond the teenage years particularly women $^{10}$. Second, Community trend and media massage push more females to seek medical attention and help to get rid of acne ${ }^{\mathbf{1 1}}$.
This study provides new evidence for nature of interrelation between using small dose of isotretinoin and occurrence psychological adverse reaction. Among all groups about one quarter of the patients suffered from episodic attack of crying and anger. This result is in agreement with the conclusion of Al-Suhaibani recent study which conducted on 202 Saudi patients (age from 18-25 years) with severe acne treated by oral isotretinoin. Twenty seven percent of participant suffered crying episode during the treatment ${ }^{\mathbf{1 2}}$. The current study also revealed that incidence of unexplainable crying episode rose three times with doubling the dose (10mg to $20 \mathrm{mg}$ daily). The result supports the causal link between isotretinoin administration and development of psychiatric adverse reactions. This finding is consistent with recent large systematic review of literatures conducted Bremener et ${ }^{\mathbf{1 3}}$ al in 2012. Reviewing literatures revealed the following sound and scientifically plausible findings that support this link: The fat-soluble nature of isotretinoin allow easy crossing bloodbrain barrier ${ }^{14}$; Functional MRI shows increase activity of hippocampal and frontal orbital areas during isotretinoin 
administration $^{15}$; Retnoic acid increase activity of dopaminergic and serotonergic systems ${ }^{\mathbf{1 6}}$; animal study show that chronic administration of isotretinoin increase depression-related behavior in mice ${ }^{\mathbf{1 7}}$. Contrary to previous literatures $^{\mathbf{1 8 , 1 9}}$, none of current series of patients has suicidal ideation or attempt. In fact, the authors of these papers specified that severe acne is an independent risk factor for attempted suicide. Furthermore, they reported that an additional risk may be present, but can't be established with certainty. Magin et al conduct extensive search in the MEDLINE, EMBASE and PsychINFO databases and find numerous case reports linking isotretinoin to depression and suicidal ideation, there is, as yet, no clear proof of an association. They suggest the possibility of a relatively rare idiosyncratic adverse effect remains ${ }^{\mathbf{2 0}}$. This conclusion is probably consistent with the current finding regarding suicide attempt. Regarding depressive symptom, the results of current study revealed gradual dose dependent increases in incidence of depression with the increasing dose of isotretinoin from $10 \mathrm{mg}$ daily to $20 \mathrm{mg}$. In conclusion, current series provide new support to the role of isotretinoin in the occurrence of the depressive symptoms in patients with acne. Which make close observation of acne patients for neuropsychiatric side effects become mandatory during isotretinoin therapy? Furthermore, prescribing it should be limited only to those with severe acne, resistant or unresponsive to several courses of antibiotics.

\section{REFERENCES:}

Al-Suhaibani S. The Impact of Oral Isotretinoin Dryness and Depression on Saudi Women in Qassim Region: A Survey. J Depress Anxiety 2016; 5:245.

Bremner JD, Shearer KD, McCaffery PJ. Retinoic acid and affective disorders: the evidence for an association. J Clin Psychiatry. 2012;73:37-50.

Charakida A, Mouser PE, Chu AC: Safety and side effects of the acne drug, oral isotretinoin. Expert Opin Drug Saf. 2004, 3: 119-129.

Cohen J, Adams S, Patten S: No association found between patients receiving isotretinoin for acne and the development of depression in a Canadian prospective cohort. Can J Clin Pharmacol. 2007, 14: 227-33.

Ellis CN, Krach KJ. Uses and complications of isotretinoin therapy. J Am Acad Dermatol. 2001;45(5):S150-S157

Emil A. Tanghetti, Ariane K. Kawata, etal. Understanding the Burden of Adult Female Acne. J Clin Aesthet Dermatol. 2014; 7(2): 22-30

Halvorsen JA, Stern RS, Dalgard F, et al. Suicidal ideation, mental health problems, and social impairment are increased in adolescents with acne: a population-based study. J Invest Dermatol. 2011;131:363370. 
Jacobs DG, Deutsch NL, Brewer $M$. Suicide, depression and isotretinoin: is there a causal risk? J. Am. Acad. Dermatol 2001;45: S168-75.

Jick S, Kremers H, Vasilakis-Scaramozza C. Isotretinoin use and risk of depression, psychotic symptoms, suicide and attempted suicide. Arch. Dermatol 2000;136:1231-36.

Kontaxakis VP, Skourides D, Ferentinos P, Havaki-Kontaxaki

BJ, Papadimitriou GN. Isotretinoin and psychopathology: a review. Ann Gen Psychiatry. 2009;8:2.

Lamberg L. Acne drug depression warnings highlight need for expert care. JAMA1998;279 (14):1057.

Layton AM. Disorders of the sebaceous glands. In: Rook's Textbook of Dermatology (8th Ed.). Burns DA, Breathnach SM, Cox $\mathrm{NH}$ et al. (Eds). Blackwell Publishing, London, UK 2010:.

Lee JW, Yoo KH, Park KY, Han TY, Li K, et al. (2011) Effectiveness: a randomized, controlled comparative study. British Journal of Dermatology 164:1369

Magin P, Pond D, Smith W. Isotretinoin, depression and suicide: a review of the evidence. $\mathrm{Br} J$ Gen Pract. 2005; 55(511): 134-138.

Magin P, Pond D. Isotretinoin, depression and suicide: a review of the evidence. $\mathrm{Br} J$ Gen Pract. 2005 Feb 1; 55(511): 134-138.

O'Reilly KC, Shumake J, Gonzalez-Lima F, Lane MA, Bailey SJ. Chronic administration of 13-cis-retinoic acid increases depression-related behavior in mice. Neuropsychopharmacology. 2006;31:1919-1927.

O'Reilly KC, Trent S, Bailey SJ, et al. 13-cisretinoic acid alters intracellular serotonin, increases 5-HT1A receptor, and serotonin reuptake transporter levels in vitro. Exp Biol Med (Maywood). 2007;232:11951203.

Ormerod AD, Thind CK, Rice SA, Reid IC, Williams $\mathrm{JH}$, McCaffery PJ. Influence of isotretinoin on hippocampal-based learning in human

subjects. Psychopharmacology (Berl) 2012;221:667-674

Rehn LM, Meririnne E, Hook-Nikanne J, et al. Depressive symptoms and suicidal ideation during isotretinoin treatment: a 12-week follow-up study of male Finnish military conscripts. J Eur Acad Dermatol Venereol. 2009;23: 1294-1297

Skroza N, Tolino E, Mambrin A, Zuber S, etal. Adult Acne Versus Adolescent Acne: A Retrospective Study of 1,167 Patients. J Clin Aesthet Dermatol. 2018 Jan; 11(1): 21-25. 